\title{
Carolina Rojas: Ayudar a los pobres. Etnografía del Estado social y las prácticas de asistencia
}

Santiago: Ed. Universidad Alberto Hurtado, 2019, pp. $366^{1}$

\section{Francisca Márquez ${ }^{2}$}

El libro de Carolina Rojas aborda, de una manera honesta y comprometida, uno de los nudos ciegos de la historia moderna de la humanidad: la desigualdad y los pobres, aquellos que carecen de los bienes básicos para cubrir sus necesidades vitales, aquellos que existen y construyen sus identidades a partir de la mirada caritativa de la Iglesia, castigadora de los mecanismos de seguridad y asistencialista del Estado social. Me detendré en tres aspectos que me parecen relevantes en este libro: a) el título y su provocación; b) los alcances del enfoque etnográfico, y c) la sospecha por la (im)posibilidad del cambio en la mirada política y social, que se deriva de los resultados de la investigación.

Partamos por el título: Ayudar a los pobres. Lo primero que habría que decir es que este es un título fuerte, quizás violento. Es fuerte, desde mi punto de vista, porque es ambiguo. Si bien anuncia la "ayuda", que tiende a llevarnos hacia la idea de la beneficencia y la asistencia, también sitúa y fija al sujeto en el estigma de la pobreza. Como un otro, porque ciertamente, hay alguien que ayuda y socorre y hay otro que recibe esa ayuda y esa asistencia: el pobre. El título lleva a pensar en otro título, el de Adela Cortina, Aporofobia. En una primera lectura podríamos decir que el título de Carolina propone justamente lo contrario,

Rojas, C. (2019). Ayudar a los pobres. Etnografía del Estado social y las prácticas de asistencia. Santiago: Universidad Alberto Hurtado.

2 Chilena. Antropóloga y doctora en Sociología, Universidad Alberto Hurtado. E-mail: fmarquezb@gmail.com 
nos invita a ayudar, no a escapar ni a temerle a ese sujeto pobre. Sin embargo, al poco entrar en la lectura, desde el prefacio de Didier Fassin, comprendemos que, tras esa ayuda, también está el miedo y la fobia a la presencia del pobre entre nosotros: la piedad y la horca son prácticas históricamente instaladas en nuestras culturas que hablan de aporofobia. Paso entonces al subtítulo del libro: Etnografía del Estado social y las prácticas de asistencia. Etno-grafía, la descripción densa e interpretativa, pero ya no del o los pobres, sino del Estado Social, y de las prácticas de asistencia que los cientos de profesionales que trabajan para el Estado hacen de manera meticulosa. El libro se mueve en este intersticio, tal como lo señala el título: del pobre asistido y del Estado asistencial de fines del siglo XX.

Paso al segundo tema, "los alcances del enfoque etnográfico". En efecto, Carolina nos ofrece el enfoque etnográfico como el soporte metodológico central para el amarre comprensivo de ambos bordes: el pobre y el Estado. Y, en esta apuesta, es ella misma, la etnógrafa y a la vez la trabajadora social, la que se ubica al centro del intersticio. Ella estuvo y está ahí, como buena trabajadora de campo, ella testimonia lo que ve y lo que escucha, ella nos habla desde adentro y desde una incómoda posición de quien se sabe observando las dolorosas gestiones del día a día de cada una de estas familias. Y eso marca la diferencia, con otros enfoques. Carolina se ubica allí donde incomoda, en un ejercicio de observación participante que, en realidad, objetiva su participación en cada lugar, sigue meticulosamente las lecciones del maestro Bourdieu, al interrogarse reflexivamente sobre este ejercicio investigativo. Desde la introducción en adelante, Carolina nos hace partícipe de esta incomodidad de su mirada, que, aunque no se desea impertinente, finalmente lo es, duele al observado más que al observador. Carolina se pregunta entonces, ¿cómo esta política de la vulnerabilidad impacta a la misma experiencia de investigación que la estudia? Dicho de otro modo, ¿en qué medida el propio objeto de estudio "afecta" las prácticas que intentan conocerlo? 
Estas preguntas ponen el dedo en la llaga, porque develan la imposibilidad de la observación participante ingenua y, a la vez, la obligan a explicitar y situar su propia posición e intereses en esta investigación. Y lo hace, lo hace con una honestidad desgarradora, que a veces se lee con pudor, al menos para mí, que creo haberme visto reflejada en mi propia experiencia de campo, en los bordes de la ciudad y en años difíciles de nuestra historia.

En términos subjetivos, el trabajo etnográfico se me presentó en muchas ocasiones adverso, agresivo e inseguro. Un ejemplo de esto fue lo que me ocurrió con Andrea, hija de Laura. Ella tenía 13 años (...). Como ya era costumbre, un día pasé a saludar a su madre y me invitaron a almorzar. Mientras Laura y yo hacíamos sobremesa, Andrea y su hermana mayor deciden ir a ver a un amigo. (...) Las niñas se acercan y me dicen "chao, tía". Entonces, le digo a Andrea "que lo pases bien". En ese momento ella se gira y muy despacio dice algo que no alcanzo a escuchar, "Ella le dijo: 'Usted es quien lo pasa bien..... (...) Las palabras de Andrea remiten a una confrontación de doble faz que me subjetiviza y por tanto me incita a negociar una identidad acerca de qué es lo que estoy haciendo. (p. 27)

Como bien reconoce Carolina, esta situación rompe con la ilusión de la etnografía de aprehender las formas de vida de los otros. "De cierta manera, las palabras de Andrea rompieron cualquier intento por superar aquella jerarquía a priori desde la cual yo, en tanto investigadora, ejercía un poder sobre ellos". Y entonces las preguntas interminables y sin respuestas posibles:

¿Cómo superar la distancia social, experiencial que me separaba de las interlocutoras? ¿Cómo conseguir la empatía etnográfica necesaria para poder explorar espacios tan íntimos, como las necesidades, los dolores y sufrimientos, pero también entrar en sus hogares y conocer sus historias? ¿Cómo franquear la distancia social, cultural y estructural existente entre nosotras, de manera de acceder a grados de horizontalidad que permitieran el establecimiento de un vínculo etnográfico? (p. 50) 
Difíciles preguntas e imposibles respuestas; salvo por la vía que sigue Carolina: tantear, empatizar, pero sobre todo objetivar no solo su trabajo, sino también sus propias contradicciones. El libro es profundamente coherente, honesto y cuidadoso en no traicionar esta propia perspectiva liminal, de investigadora, de trabajadora social y de profundo compromiso afectivo y político.

El tercer aspecto es la pregunta sobre por la (im)posibilidad del cambio en la mirada política y social de la desigualdad. Porque Carolina, aunque habla de pobres y pobreza, en realidad habla de desigualdad. De un país y una sociedad que no piensa a todos como iguales. Como bien dice Didier Fassin, la "cuestión social" ha sido planteada tanto desde el punto de vista del fenómeno de la pobreza como de la gestión de los pobres. "Gestión de los pobres”, concepto que ciertamente es de una violencia simbólica feroz. Más aún si vemos, como se concluye de la lectura de este libro, que dicha gestión pareciera ser de las más ineficientes e ineficaces imaginables. Cito a Carolina,

en una evaluación realizada por y para el propio Banco Mundial que para el período entre 2003 y 2006 el impacto del programa [Chile Solidario] en términos de la línea de la pobreza nacional no fue superior a 0,1 puntos. Pero a pesar de esto, esta política ha logrado mantenerse y consolidarse durante ya más de trece años. (p. 337).

En este ejercicio etnográfico hay una cita desgarradora, y resume bien lo anterior:

Clara me relató un momento emblemático en su experiencia como Apoyo Familiar: "Durante el desarrollo de la última sesión con una familia con la que había trabajado veinticuatro meses me dijeron: ¿¿No va a venir más? ¿Se acabó? Pero mi vida no cambió nada, soy igual de pobre que hace dos o cinco años"'. (p. 65)

Estas frases resumen bien no solo Chile Solidario, sino parte importante de las políticas sociales neoliberales. Este país, así como 
muchos otros, se ha engolosinado con las ingenierías sociales, pero ha perdido el norte respecto de las transformaciones que la sociedad requiere para ser más justa e igualitaria. "Lo único certero, señala Carolina, es que el proceso de intervención justificó un vínculo, un fichaje, la aplicación de ciertos dispositivos, la asignación de recursos, la creación de instituciones y la producción y movilización de determinadas emociones", para luego advertir que, con ello, "se han resignificado las desigualdades, las experiencias de los pobres y las responsabilidades del Estado” (p. 336), pero resignificar no es transformar, al menos así lo muestran los datos que ella nos presenta.

La política de la vulnerabilidad corresponde entonces a una techné (en el sentido aristotélico del término), es decir, un acto productivo que crea una realidad que antes no existía: una población, un lenguaje, una institucionalidad, un problema, un campo de trabajo, un sujeto y una moral ligada a una disposición y responsabilidad de ayuda. Pero también, a una "habilidad" institucional, política, económica y sobre todo de gestión de lo social.

Paradojal porque luego ella nos advierte que la legitimidad de esta política no se debe a su eficacia en cuanto a los resultados alcanzados en la eliminación de la extrema pobreza, la superación de la desigualdad o el resguardo de las familias en situación de riesgo (p. 340). Carolina sitúa el relativo éxito de esta política en los intangibles, por llamarlos de algún modo, en la "coherencia técnica y belleza en tanto dispositivo institucional, es decir, a su eficacia de modelización. Ciertamente, lo que más se valora son su metodología y sus sistemas de gestión, así como los vínculos y el sentimiento de reconocimiento que causan a nivel de beneficiario" (p. 340). Permítanme decirlo, pero esta conclusión es brutal y, más aún, ya lo advertíamos quienes pudimos ver la puesta en marcha de este Chile Solidario. Todo parecía cambiar en aquellos tiempos, para que nada cambiara. Lo grave es que esta ingeniería metodológica de la que tanto nos vanagloriamos, hoy es exportada a países tan diversos como Haití, Paraguay, El Salvador, Jamaica, Mozambique... 
Una política económicamente precaria y restringida y al mismo tiempo moral y subjetiva (p. 342); todo se resuelve, por tanto, en la relación directa con las familias. Lo relevante de este punto es mostrar que en general la asistencia como dominio de acción pública no es objeto de lucha de interés o de competencia de poder entre los actores sociales, sino que, desde lo marginal y burocrático que es, se comparte o reparte entre distintas profesiones ( $p$. 344). Yo agregaría a esta afirmación conclusiva, que este es uno de los mayores logros de este sistema político neoliberal. Hacer creer a los más excluidos, uno: que este es un asunto de esfuerzo de las propias familias; dos, que las capacidades/habilidades se adquieren de esta relación uno a uno entre la familia y el Estado; tres, que aquí nada tiene que hacer la organización social, las identidades comunitarias, en síntesis, aunque resulte paradojal, la solidaridad como vínculo que nos amarra y nos compromete como sociedad. Gran paradoja y gran éxito de la una sociedad que ha aprendido a convivir y tolerar la desigualdad, Porque, finalmente, los pobres se dividen entre los habilitados y los no habilitados, como ya lo instalara en el mundo académico y político el CEP el año 1995. Ese mismo año, sin embargo, hubo otro estudio: El Informe de la decencia, de Javier Martínez y Margarita Palacios, que advertía que el problema de nuestra sociedad era otro, y refería a la deslegitimidad del Código de la decencia, y del aprendizaje brutal que muchos jóvenes hacían de las reglas del mercado. Aprender a valerse de estas reglas, cueste lo que cueste, era percibido ya en esos años, como la única posibilidad de surgir y superar la pobreza y la desigualdad en la que vivían sus padres. En los términos de este informe, esas eran las habilidades morales si se quería superar la pobreza. En síntesis, ni el Estado, ni la sociedad en su conjunto está comprendiendo, que el aislamiento que hoy viven las familias más excluidas de la sociedad ha dejado espacio para que los feroces códigos del mercado - del mercado inmobiliario, del mercado del narco, del mercado del consumo- ocupen el lugar que debieron tener la solidaridad, la reciprocidad y el don. El libro de Carolina así lo confirma, y por eso toda su vigencia y desgarro. 
Pero Carolina agrega algo más, y que contradice profundamente las olas de feminismo que hemos podido apreciar este último tiempo: El modelo crea

un proceso de sexuación de la vulnerabilidad y, de paso, de la asistencia, en la medida que se les asigna un valor diferencial a los sexos. De esta manera, quien tiene el derecho legítimo de la asistencia es la mujer, con lo cual se subentiende que la vulnerabilidad de hombres es tomada como una falta de responsabilidad masculina vinculada a su participación en el mundo del trabajo. Siendo así, se asume que su situación debe ser resuelta a nivel del espacio del mercado o de la seguridad social que le ofrece su estatus de trabajador. (p. 345)

De esta manera, el género no es más la causa de las desigualdades, sino la consecuencia de una política que reintroduce lo social en el Estado mediante la fijación de tipos de relación y de estigma de género entre hombres y mujeres pobres.

Finalmente, la conclusión que arroja este estudio es clara:

de la experiencia chilena contemporánea se desprende la idea de que lo neoliberal del quehacer social del Estado tiene más que ver con la regulación y control biopolítico de los individuos. Esta paradoja conduce al desarrollo de prácticas de intervención ambiguas que finalmente se sostienen en relaciones de tipo intersubjetivas de ayuda caritativa. (p. 356)

La moral neoliberal operaría construyendo una ciudadanía ética que se sostiene en el cuidado o preocupación por uno mismo y sus más próximos: la familia; no el barrio, ni la clase, ni la sociedad. De ahí la legitimidad que adquiere una acción estatal de proximidad como es la visita domiciliaria. Tal cual como hace un siglo atrás.

El liberalismo político viene en auxilio del neoliberalismo económico, insistiendo en la determinación individual de las condiciones sociales, en la capacidad de decisión de cada uno y en la preeminencia de la libertad sobre la igualdad (p. 32). Hablar de 
pobreza sigue siendo eludir las desigualdades. Tal como se titula el sexto capítulo, "la ayuda no se exige, se agradece", porque dejó de ser un derecho de justicia social. 